\title{
How to reduce your cancer risk: mechanisms and myths
}

\author{
This article was published in the following Dove Press journal: \\ International Journal of General Medicine \\ 7 April 201I \\ Number of times this article has been viewed
}

\author{
Zeina Nahleh' \\ Narinder Singh Bhatti ${ }^{2}$ \\ Meenakshi $\mathrm{Mal}^{2}$ \\ 'Division of Hematology-Oncology, \\ Department of Internal Medicine, \\ TTUHSC-Paul L Foster School of \\ Medicine, El Paso, TX, USA; '2Dayanand \\ Medical College and Hospital, \\ Ludhiana, Punjab, India
}

\begin{abstract}
Cancer prevention continues to be a high research priority and the most optimal way to ultimately lower the economic and psychological burden of cancer. Many known risk factors associated with cancer are related to dietary and lifestyle factors and can be avoided. These risk factors include among others, smoking, obesity, alcohol, physical inactivity, and carcinogens in diet. This article reviews the biological mechanisms leading to cancer in association with these factors, highlights important achievable cancer prevention methods, addresses commonly asked questions about lifestyle and cancer, and dispels some of the myths about cancer prevention.

Keywords: cancer prevention, cancer risk, lifestyle, diet
\end{abstract}

\section{Introduction}

"Prevention" in medicine, refers to an action taken to decrease the chance of getting a disease or condition. According to the National Cancer Institute, ${ }^{1}$ cancer prevention involves avoiding risk factors, such as smoking and increasing protective factors that may decrease a person's chance of developing cancer. In general, cancer is caused by multiple genetic defects that can result from exposure to environmental, dietary, and lifestyle risk factors, as well as infectious agents. The gradual carcinogenetic changes in the biological behavior of a susceptible clonogenic population of cells may span years or decades. Many of the known risk factors can be potentially avoided. However, eliminating potential risk factors by no means guarantees that one will not actually get cancer due to the interplay of several insults rendering some people more susceptible and genetically predisposed than others. Also cancer is not a single disease but a group of related diseases. Nevertheless, learning about and utilizing protective factors is an important first step toward cancer prevention. Also, there has been a revived interest by federal as well private agencies in promoting cancer prevention and risk reduction research and strategies in view of rising health care cost and its burden on the economy. Cancer prevention on a large scale would be the optimal way to ultimately lower the physical, emotional, and financial burden of cancer as well as improve the overall health of cancer survivors by reducing the risk of cancer recurrence and the development of second cancers. A review of all possible chemical or biological cancerpromoting factors is beyond the scope of this review. The purpose of this article is to review the biological mechanisms leading to cancer in association with lifestyle factors, describe some of the general cancer prevention methods, and address common questions about the associations between dietary and lifestyle measures with cancer. In addition, this article aims at dispelling some of the myths about cancer prevention. 
It emphasizes simple practical strategies aimed at reducing the risk of developing cancer and avoiding potentially known risk factors.

\section{Smoking}

Cigarette smoking is the major single cause of death from cancer in the United States (US). ${ }^{2-10}$ Smoking is directly responsible for $85 \%$ to $90 \%$ of lung cancer deaths, $70 \%$ of deaths from oral and laryngeal cancer, more than $50 \%$ deaths from esophageal cancer, $40 \%$ of deaths from bladder and kidney cancer, about $30 \%$ of deaths from pancreatic cancer, and a significant number of deaths from cancer of the stomach and cervix..$^{2-5}$ Also, the influence of smoking on cancer risk is greatly associated with the duration and time effect. ${ }^{5}$ For example, if one stops smoking immediately, a progressive decline in the risk of developing lung cancer occurs, but it would take 15 to 20 years before the risk is close to that of a nonsmoker. ${ }^{6}$ In the US, effective tobacco control efforts have resulted in substantial declines in smoking and smoking-related cancer deaths. As an example, nearly $40 \%$ of reductions in male lung cancer deaths since the early 1990s have been attributed to smoking declines in the last half century. ${ }^{6}$ Nevertheless, tobacco use still remains the single, largest preventable cause of disease and premature death in the US and results in nearly half a million premature deaths each year, of which nearly one-third are due to cancer. ${ }^{6}$ Despite the increased awareness and the fact that many adult smokers want to quit, and effective interventions do exist, only a small proportion of tobacco users do try treatment. ${ }^{5}$ This gap may represent a major national quality-of-care problem. Also, another aspect of tobacco use known as smokeless tobacco is becoming prevalent and may increase in the US. ${ }^{5}$ Therefore, increased awareness is important to understand net population harms related to use of smokeless tobacco which should be the focus of more future research. Prevention, especially among youth, and cessation are the cornerstones of strategies to reduce tobacco use. Tobacco use is a critical and chronic problem that requires close attention from health care providers, health care organizations, and research support organizations. ${ }^{5}$

The mechanism linked to the carcinogenic effect of tobacco is the presence of a large number of identified carcinogens in these products. Around 4000 chemicals have been identified in cigarette smoke, among which more than 60 are established carcinogens. ${ }^{10}$ The strongest carcinogens are polycyclic aromatic hydrocarbons (PAHs), $N$-nitrosamines, and aromatic amines. These compounds occur in small quantities, typically about
5 to 200 ng per cigarette. The most prevalent carcinogens are aldehydes and other volatile organic compounds such as benzene and butadiene. These compounds are found in quantities of 10 to $1000 \mu \mathrm{g}$ per cigarette. In relation to human lung cancer, arguably the most important carcinogens are PAHs such as benzo $[a]$ pyrene and the tobacco-specific nitrosamine 4-(methylnitrosamino)-1-(3-pyridyl)-1-butanone (also known as nicotine-derived nitrosaminoketone [NNK]). Carcinogens form the link between nicotine addiction and lung cancer. Nicotine is not generally considered to be a carcinogen, although it can induce tumors under certain special conditions such as hyperoxia. Nicotine can also be converted into carcinogens such as NNK in the body. ${ }^{10}$ The cigarette is a disastrous nicotine-delivery device, because more than 60 carcinogens, including PAHs and NNK, accompany nicotine in each puff. Although the dose of each carcinogen per cigarette is quite small, the cumulative dose in a lifetime of smoking is substantial.

\section{Healthy weight}

Obesity and overweight are two terms referring to the range of weight that is considered higher than that of the normal general population. The body mass index (BMI) is the number by which the range of obesity or overweight is calculated (by dividing the weight of the person by the square of their height). An adult who has a BMI between 25 and 29.9 is considered overweight and one with a BMI of 30 or higher is considered obese. ${ }^{11}$ Both of these conditions are considered high risk for certain disease conditions and health problems, such as high blood pressure, diabetes, stroke, and more recently cancer. ${ }^{12-15}$ The issue of obesity is of paramount importance in the US since it is on the rise. ${ }^{11}$ It is estimated that more than 40,000 cancer diagnoses each year and around $20 \%$ of all cancer-related deaths are caused by obesity, ${ }^{14,16}$ including $15 \%$ of cancer deaths in men and $20 \%$ in women. ${ }^{14}$ The continuously rising obesity heralds a worrisome trend. Results from the 1999-2000 National Health and Nutrition Examination Survey showed that an estimated $64 \%$ percent of US adults are either overweight or obese. ${ }^{11}$ This reflects an increase of 7.6 percentage points since $1994^{11}$ with around $30 \%$ percent of adults age 20 and older - nearly 59 million people - having a BMI of 30 or greater, compared with $23 \%$ in 1994 . More recently, Centers for Disease Control and Prevention figures released in 2010 showed that 2.4 million more Americans became obese between 2007 and 2009. Therefore, approximately one-third of all the US adult population, or 72.5 million people, are now obese. ${ }^{10} \mathrm{~A}$ rise in cancer because of obesity 
is therefore expected in the coming years. ${ }^{17} \mathrm{~A}$ link between obesity and risk of cancer has been reported at several organ sites, including colon, breast (in postmenopausal women), endometrium, esophagus, gallbladder, and pancreas. ${ }^{12,17}$ The American Institute of Cancer research projects there will be more than 103,000 new cancer cases caused by excess body fat in $2010 .{ }^{17}$ Forty-nine percent are projected to be endometrial cancers, followed by esophageal cancers at $35 \%$ and pancreatic cancers at $28 \%$. If the current worrisome trend is not interrupted, those numbers are anticipated to keep increasing over the next several years in response to the increased obesity rates each year. ${ }^{17}$

The underlying mechanisms linking obesity to cancer have been based on potential alterations in the metabolism of endogenous hormones, including sex steroids, insulin, and insulin-like growth factors, which can lead to distortion of the normal balance between cell proliferation, differentiation, and apoptosis. ${ }^{13}$ Also high levels of certain cytokines such as interleukin-6 and tumor necrosis factor in obese individuals can promote carcinogenesis and the proliferation of normal cells into malignant cells. ${ }^{1}$ In breast cancer, both an increased risk of developing breast cancer and dying from the disease have been described in obese postmenopausal women and are believed to be due to increased levels of estrogen in these women. ${ }^{18}$ Before menopause, the ovaries are the primary source of estrogen. However, adipose tissues become the main source of estrogen after menopause. Estrogen levels in postmenopausal women are $50 \%$ to $100 \%$ higher among obese versus normal weight women. ${ }^{18}$ Estrogen-sensitive tissues are therefore exposed to more estrogen stimulation in overweight and obese women, leading to a more rapid growth of estrogen-responsive breast tumors. The molecular basis for estrogen carcinogenesis is still unclear. One proposed mechanism is that excess estrogen exposure leads to elevated generation of reactive oxygen species (ROS), for example 15- $\mathrm{F}_{2 \mathrm{t}}$-isoprostane, through estrogen-receptor and/or metabolic activation pathways. ${ }^{19-22}$ These ROS, along with ROS from external sources, such as smoking and dietary oxidants, may exhaust human antioxidant defense capability, leading to oxidative stress. ${ }^{23-27}$ The recent prospective Shanghai Women's Health Study, which included 74,942 Chinese women aged 40 to 70 years, suggested an association between levels of ROS (isoprostanes) with breast cancer and BMI. ${ }^{19,28}$ An increased risk of breast cancer was associated with elevated urine levels of isoprostanes, mainly observed among women with a high BMI, and the association became stronger with increasing BMI. Women with a BMI $>28$ had a higher level of isoprostanes whereas weight loss was associated with a decreased level of these ROS. ${ }^{19}$ The study also suggested an inverse association with isoprostanes levels among premenopausal women or those with a low BMI. This is consistent with the fact that several suggested protective factors for breast cancer risk, such as physical activity and parity (normal pregnancy), may be associated with significantly elevated levels of lipid peroxidation and low oxidative stress. ${ }^{29,30}$ Compared with postmenopausal women, isprostanes levels were lower among healthy premenopausal women. ${ }^{19}$ An important association therefore exists between increased oxidative stress, breast cancer, and increased BMI mostly in postmenopausal women.

Another potential mechanism linking obesity with an increased risk of developing many cancers including breast and colon cancer is hyperinsulinemia and insulin resistance, mostly via the insulin-like growth factor (IGF) axis. ${ }^{31}$ IGF-1 binds and activates both insulin and IGF receptors that are expressed on a number of cells including colon cancer cells. IGF-1-mediated receptor activation leads to cell growth and proliferation, and inhibition of apoptosis. ${ }^{31}$ Mechanisms by which obesity increases risk of other carcinomas are not well described. One of the leading mechanisms proposed for esophageal and gastric cancers has been increases in gastric reflux due to obesity. However, this remains somewhat controversial and more research is needed to further examine the issue. ${ }^{32}$

\section{Physical activity and exercise}

Physical activity is any bodily movement produced by skeletal muscles that result in the expenditure of energy. It is an important component of energy balance. Physical activity can improve overall health by controlling weight, high blood pressure, and diabetes. In addition, researchers have been interested to learn the effect of physical activity on the risk of cancer. Nearly 170 observational epidemiological studies of cancer risk and physical activity have been conducted at different cancer sites. ${ }^{33-35}$ The evidence of decreased cancer risk with physical activity has been found convincing for breast and colon cancer, probable for prostate, and possible for lung and endometrial cancer. ${ }^{33}$ Colorectal cancer has been among the most extensively studied cancers in relation to physical activity. ${ }^{36}$ Adults who increase their physical activity, either in intensity, duration, or frequency, can reduce their risk of developing colon cancer by $30 \%$ to $40 \%$ relative to those who are sedentary regardless of BMI, with the greatest risk reduction seen among those who are most active. ${ }^{36,37}$ The magnitude of the protective effect appears greatest with high-intensity activity, although the optimal 
levels and duration of exercise are still difficult to determine because of differences between studies. It is estimated that 30 to 60 minutes of moderate to vigorous physical activity per day is needed to protect against colon cancer. ${ }^{36}$

Physical activity may affect colon cancer risk in various ways, including reducing the fecal transit time, accelerating the movement of food through the intestine, thereby reducing the length of time that the bowel lining is exposed to mutagens, reducing the inflammation and insulin resistance, and modifying hormonal metabolism. ${ }^{37,38}$ Numerous studies have looked at the association between physical activity and breast cancer, showing that postmenopausal women who are physically active have up to an $80 \%$ reduction in cancer risk. ${ }^{39}$ The risk reduction could be attributed to a lower BMI, or to the alterations in hormone levels. Vigorous physical activity may decrease the exposure of breast tissue to circulating estrogen, potentially decreasing the risk of breast cancer. ${ }^{40,41}$ It is less clear that physical activity reduces the risk of premenopausal breast cancer. ${ }^{38,39}$

Other cancers have been reported to be reduced by exercise and physical activity but results are less consistent. The most active women have a $20 \%$ reduced risk of endometrial cancer compared with the least active women, according to a meta-analysis of seven cohort studies. ${ }^{42}$ Similarly, a meta-analysis found evidence that people who participate in higher levels of recreational physical activity have a lower risk of lung cancer. ${ }^{43}$ However, other studies looking into physical activity and lung cancer risk have been inconsistent. ${ }^{43-47}$ Some studies have shown a reduced risk of pancreatic cancer for people doing moderate amounts of physical activity, ${ }^{48,49}$ but other studies do not show such an association. ${ }^{50-52}$ There is evidence that men who are physically active have a reduced risk of prostate cancer. ${ }^{53-56}$ Other reports have been less suggestive..$^{57,58}$ One large cohort study showed no association of physical activity with prostate cancer risk in white men, although there was a risk reduction for black men. ${ }^{58}$ Physical activity may also decrease the risk of pancreatic cancer. ${ }^{59-61}$ The proposed mechanism includes insulin resistance as an etiologic factor in the development of pancreatic neoplasms. ${ }^{60}$

\section{Diet}

The importance of diet as a major cause of cancer has been suggested repeatedly. ${ }^{63-80}$ Dietary patterns, foods, nutrients, and other dietary constituents are thought to be closely associated with the risk for several types of cancer and as much as $40 \%$ of cancers are potentially attributable to dietary factors. ${ }^{65}$ Dietary factors account for about $30 \%$ of all cancers in
Western countries and approximately up to $20 \%$ in developing countries. Diet is considered second only to tobacco as a preventable cancer cause. ${ }^{67}$ It has been estimated that $30 \%$ to $40 \%$ of all kinds of cancers can be prevented with a healthy lifestyle and simple dietary measures. ${ }^{63,66}$ While it is not yet possible to provide quantitative estimates of the overall risks, the research generated from past dietary programs has advanced our understanding of broad scale interventions which include messages such as simply the use of five fruits and vegetables a day. More research is needed, however, to identify the determinants of dietary behavior, the interaction of dietary behavior, weight control, and physical activity, more targeted diet-related interventions, and new methods of dietary assessment for tracking the impact of interventions and developing effective behavioral interventions. ${ }^{69}$

As noted earlier, studies conducted over the years have suggested a strong correlation between diet and cancer. A comprehensive worldwide report ${ }^{65}$ compiled by World Cancer Research Fund and American Institute for Cancer Research indicated a significant relation between lifestyle, including food consumption, and cancer prevention. While recognizing the limitations and lack of rigorous scientific validation of many dietary studies as well as the need for more and better research, there are some interesting observations that deserve particular attention. In general, the following dietary elements have been linked with cancer risk: ${ }^{68}$ Aflatoxins in foods causes liver cancer, Chinese-style salted fish increases the risk for nasopharyngeal cancer, preserved meat and red meat may increase the risk for colorectal cancer, salt-preserved foods and high salt intake may increase the risk for stomach cancer, and very hot drinks and foods may increase the risk for cancers of the oral cavity, pharynx, and esophagus. High-fat diets have been associated with an increase in the risk of cancers of the colon and rectum, prostate, and endometrium. ${ }^{62}$ The association between high-fat diets and breast cancer is much weaker. Also excessive intake of sugar and other highly refined carbohydrates may contribute to insulin insensitivity, alterations in the amount and distribution of body fat, and increased concentrations of growth factors that may promote the growth of cancers. ${ }^{62}$ On the other hand, many dietary factors have been reported to have some protective values for cancer prevention. Vegetables and fruits contain specific phytochemicals, such as carotenoids, flavonoids, terpenes, sterols, indoles, and phenols, which may have protective effects against certain cancers. ${ }^{62}$ Garlic, used for flavoring in cooking is unique because of its high sulfur content. Increased intake of garlic has been associated with decreased risk of colorectal 
cancer, ${ }^{71}$ stomach cancer ${ }^{72}$ and a $50 \%$ reduction in prostate cancer risk. ${ }^{73}$ The health benefits of the allium compounds contained in garlic and other vegetables in the onion family have been publicized widely, but insufficient evidence exists at this point to support a specific role for this vegetable in cancer prevention. Cruciferous vegetables including broccoli, cauliflower, cabbage, Brussels sprouts, bokchoy, and kale include several components that have been highlighted to lower cancer risk. These include glucosinolates, crambene, indole-3-carbinol, and, especially, isothiocyanates which are derived from glucosinolates. ${ }^{74-76}$ Several laboratory studies have suggested that cruciferous vegetables help regulate a complex system of bodily enzymes that defend against cancer. Components of these vegetables have shown the ability to stop the growth of cancer cells in various tissue and animal models, including tumors of the breast and colon. ${ }^{75,76}$ Epidemiologic studies have also suggested an inverse correlation between consumption of cruciferous vegetables and the risk of many cancers including the risk of lung, stomach, colorectal, bladder, and other cancers. ${ }^{74-76}$ The relation between cruciferous vegetable intake and breast cancer risk has also been suggested in epidemiological studies but is less clear. ${ }^{77}$

\section{Vitamins and supplements}

Despite becoming a growing field in health care mainly because of consumers' interest and affordability, conflicting literature exists on the benefit of many vitamins and nutritional supplements, especially in association with cancer prevention. ${ }^{81-104}$ Our experience has been that healthy consumers as well as cancer patients seek vitamins and dietary supplements to boost their immune system, improve their quality of life, prevent occurrence or recurrence of cancer, and obtain many other benefits despite the absence of scientific evidence and even potential toxicity in some instances. ${ }^{81}$ Some reports such as the unproven "triage theory" $82-84$ have suggested a rationale for a causal link between chronic modest deficiency of micronutrients (essential minerals, vitamins, amino acids, and fatty acids) and the many degenerative diseases accompanying aging such as cancer, immune dysfunction, cognitive decline, cardiovascular disease, and stroke. Micronutrient deficiencies are common. For example, over half of the US population have inadequate intakes of magnesium ${ }^{84}$ almost all African-Americans are extremely low in vitamin $\mathrm{D},{ }^{85}$ and much of the population is low in a variety of other micronutrients (eg, omega-3 fatty acids, potassium, calcium, vitamin $\mathrm{C}$, vitamin $\mathrm{E}$, vitamin $\mathrm{K}$ ). ${ }^{82,86}$ No overt pathologies have been associated with marginal to moderate levels of deficiency, yet it has been suggested that pathology can be insidious. ${ }^{84}$ Unfortunately, as noted above there are significant limitations to experimental approaches available for demonstrating a causal relation between micronutrient deficiency and cancer. ${ }^{87,88} \mathrm{~A}$ critical analysis of this large literature is beyond the scope of this manuscript, but owing to recent public debate related to vitamin $\mathrm{D}$, we will review here the existing literature on vitamin $\mathrm{D}$ and cancer. A recent report from the Institute of Medicine ${ }^{89}$ concluded that the prevalence of vitamin D inadequacy in North America has been overestimated. It identified further research and clinical priorities, including reassessment of laboratory ranges for 25-hydroxy vitamin $\mathrm{D}$, to avoid problems of both under- and over treatment.

\section{Vitamin D and cancer}

Two major forms of vitamin $\mathrm{D}$ are important to humans: vitamin $\mathrm{D}_{2}$, or ergocalciferol, and vitamin $\mathrm{D}_{3}$, or cholecalciferol. Vitamin $\mathrm{D}_{2}$ is made naturally by plants, and vitamin $\mathrm{D}_{3}$ is made naturally by the body when the skin is exposed to ultraviolet radiation (in particular UVB radiation) in sunlight. Vitamin $\mathrm{D}_{2}$ and vitamin $\mathrm{D}_{3}$ can also be commercially manufactured. ${ }^{90}$ Dietary sources rich in vitamin D include fatty fish, fish liver oil, eggs, meat, cheese, and fortified foods, such as milk, juices, yogurt, bread, and breakfast cereals. ${ }^{90}$

A possible role for vitamin $\mathrm{D}$ in cancer prevention has been investigated somewhat extensively but the evidence of potential benefit is limited and inconsistent. ${ }^{91-100}$ There are no current recommendations to use vitamin D supplements to reduce the risk of any type of cancer. We here review some of the data that sparked some debate about the use of vitamin $\mathrm{D}$ for cancer prevention. Large randomized clinical trials investigating the effects of vitamin D intake on bone health have suggested that higher vitamin D intake may reduce the risk of cancer. ${ }^{91}$ A study involving nearly 1200 healthy postmenopausal women who took daily supplements of calcium (1400 mg or $1500 \mathrm{mg})$ and vitamin D $(25 \mu \mathrm{g}$ vitamin $\mathrm{D}$, or $1100 \mathrm{IU}$ - a relatively large dose) or a placebo for 4 years found that women who took the supplements had a $60 \%$ lower overall incidence of cancer; ${ }^{91}$ however, the study did not include a vitamin D-only group. Two cohort studies, the Nurses' Health Study, and the Health Professionals Follow-Up Study, have shown an inverse association between plasma vitamin D levels and colorectal cancer. ${ }^{92}$ Vitamin D metabolites help maintain a normal calcium gradient in the colon epithelial crypts ${ }^{92}$ and high serum levels of $25(\mathrm{OH}) \mathrm{D}$ are associated with markedly decreased proliferation of noncancerous but high-risk epithelial cells in the colon. ${ }^{93}$ 
In another study, the vitamin D intakes of 3000 people from several Veterans Affairs medical centers were examined to determine whether there was an association between intake and advanced colorectal neoplasia. ${ }^{94}$ Individuals with the highest vitamin D intakes ( $>16 \mu \mathrm{g}$, or $645 \mathrm{IU}$, per day) had a lower risk of developing advanced neoplasia than those with lower intakes.$^{94}$ Other reports also suggest an inverse association between vitamin D levels and risk of death due to colorectal cancer. ${ }^{95,96}$ However, data on the association between vitamin $\mathrm{D}$ and breast cancer risk are conflicting. In the Women's Health Initiative, calcium plus vitamin D supplementation for an average of 7 years did not reduce the incidence of invasive breast cancer compared with placebo. ${ }^{97}$ However, other observational studies reported that intake of $2000 \mathrm{IU} /$ day of vitamin D3, and, when possible, very moderate exposure to sunlight, could raise serum $25(\mathrm{OH})$ D to $52 \mathrm{ng} / \mathrm{mL}$, a level associated with reduction by $50 \%$ in incidence of breast cancer. ${ }^{98}$ Similarly, epidemiological studies have yielded inconsistent associations between vitamin $\mathrm{D}$ status and other cancers, like pancreatic and prostate cancer. Some studies even suggest that there may be an increased risk of prostate cancer associated with increased serum 25-hydroxyvitamin D [25(OH)] or vitamin D levels. ${ }^{99}$ In contrast, other prospective cohort studies have shown that higher $25(\mathrm{OH}) \mathrm{D}$ score was associated with a lower risk of pancreatic cancer. ${ }^{100}$

\section{Alcohol}

Most people recognize that heavy alcohol use can cause health problems but many people may not be aware that alcohol use can increase cancer risk. A causal association has been suggested between alcohol consumption and many cancers, including cancers of the oral cavity, pharynx, larynx, esophagus, liver, colon, rectum, breast cancer, and lung cancer. ${ }^{105-107}$ In women, alcohol consumption has been established as a risk factor for breast cancer and may also increase risk of breast cancer recurrence, particularly among postmenopausal and overweight and obese women. ${ }^{108}$ The combined use of alcohol and tobacco increases the risk of these cancers far more than the effects of either drinking or smoking alone. ${ }^{109}$ This is of significant importance especially in countries such as the US, where it is estimated that 52\% of adults are current regular drinkers, consuming at least 12 drinks per year. ${ }^{109}$

The exact mechanism by which alcohol affects cancer risk is not completely understood but there are several suggested potential factors. Alcohol may act as an irritant, especially in the mouth and throat. Cells that are damaged may develop
DNA changes that can be a precursor of cancer. ${ }^{105}$ Alcohol may also act as a solvent, helping other harmful chemicals, such as those found in tobacco smoke, to enter the cells lining the upper digestive tract more easily; this may help explain why the combination of smoking and drinking is much more likely to cause cancers in the mouth or throat than either smoking or drinking alone. ${ }^{109}$ Another mechanism focuses on acetaldehyde, a suspected carcinogen that is the first metabolite formed as the body breaks down alcohol. Recent reports indicate that polyamines, natural compounds involved in cell growth, interact with acetaldehyde and trigger reactions that damage DNA, a situation that can lead to the developmentof cancer. ${ }^{105,110}$ Polyamines cause the conversion of acetaldehyde into crotonaldehyde, an environmental pollutant known to cause cancer in animals. ${ }^{110,111}$

\section{Cancer chemoprevention research}

There have been numerous attempts to use chemoprevention for decreasing the risk of certain cancers. The selective estrogen-receptor modulator (SERM) tamoxifen became the first US Food and Drug Administration (FDA)-approved agent for reducing breast cancer risk, but did not gain wide acceptance for prevention, largely because it increased endometrial cancer and thromboembolic events. ${ }^{112}$ The FDA subsequently approved the SERM raloxifene for breast cancer risk reduction following its demonstrated effectiveness in preventing invasive breast cancer in the Study of Tamoxifen and Raloxifene. Raloxifene caused less toxicity (versus tamoxifen), including reduced thromboembolic events and endometrial cancer. ${ }^{112}$ The FDA also approved the use of a vaccine (Cervarix ${ }^{\circledR}$; GlaxoSmithKline, London, UK) for use in girls and women ages 10 years through 25 years to prevent cervical cancer and precancerous lesions caused by human papillomavirus types 16 and 18, and most recently the quadrivalent human papillomavirus (types 6, 11, 16, 18) recombinant vaccine $\left(\right.$ Gardasi ${ }^{\circledR}$; Merck \& Co., Inc, Whitehouse Station, NJ) to prevent anal cancer in men and women aged 9 through 26 years. ${ }^{113}$ Prevention of prostate cancer has also received significant attention. However, the FDA denied approval of two initially promising 5-alpha reductase inhibitors dutasteride and finasteride for the prevention of prostate cancer following the results of two large randomized trials Prostate Cancer Prevention Trial and Reduction by Dutasteride of Prostate Cancer Events, citing possible links to heightened incidence of high-grade tumors. This remains, however, somewhat controversial. ${ }^{114}$ Efforts to use isolated vitamins and nutrients have proved less successful. The Selenium and Vitamin E Cancer Prevention Trial and 
the Physician's Health Study II showed negative results for vitamin $\mathrm{E}$, vitamin $\mathrm{C}$, and selenium supplementation on decreasing prostate cancer risk. ${ }^{114}$

Cancer prevention based on dietary and lifestyle interventions remains a hot research topic. However, inconsistencies and conflicting information call for further rigorous research trial designs possibly focusing on highrisk populations identified through genomic and molecular research.

\section{Summary and recommendations}

1. Smoking cessation: one could argue that the single most important behavioral modification that can be achieved toward minimizing personal cancer risk is to quit smoking. All types of tobacco products contain nicotine and cancer-causing substances. Both smokeless tobacco and smoking tobacco are known to cause cancers in humans and there is no known safe level of tobacco use.? People who use any type of tobacco product should be urged to quit. For those who use smoking tobacco, the risk of premature death and the chance of developing cancer depend on many factors, including the number of years a person smokes, the number of cigarettes smoked per day, the age at which smoking began, and the smokers' symptoms at the time of quitting. ${ }^{7-10}$ However, people who quit smoking, regardless of their age, are less likely than those who continue to smoke to die from smokingrelated illness. Prevention and cessation among youth cannot be overemphasized. Also, among people who have already developed cancer, quitting smoking reduces the risk of developing a second cancer. ${ }^{9}$

2. Preventing weight gain and maintaining a healthy weight: this approach can potentially reduce the risk of many cancers. Overweight status and obesity are associated with increased risk of cancers at several sites. ${ }^{12-17}$ These findings are supported by both clinical as well as epidemiological studies. Overweight and obese individuals have more adipose tissues, which can produce hormones such as insulin or estrogen that could promote carcinogenic mechanisms. Obesity may account for a third of several major cancers - colon, breast (postmenopausal), endometrial, kidney, and cancer of the esophagus. Obesity is becoming epidemic in the US and the trend is very worrisome. Experts recommend that people establish habits of healthy eating early in life to prevent weight gain and obesity. ${ }^{15}$ Individuals who are already overweight or obese are advised to avoid additional weight gain, and to lose weight through balancing caloric intake with physical activity, choosing foods low in calories, and avoiding large portion sizes. Even a weight loss of only $5 \%$ to $10 \%$ of total weight has been suggested to provide significant health benefits. ${ }^{15}$

3. Physical activity: scientific evidence indicates that physical activity may reduce the risk of several types of cancer, including cancers of the breast and colon, and can provide other important health benefits. Physical activity acts in a variety of ways to impact cancer risk. Regular physical activity helps maintain a healthy body weight by balancing caloric intake with energy expenditure. It also helps to minimize the negative association between lack of physical activity and cancer, including changes in endogenous sexual and metabolic hormone levels and growth factors, and to decrease obesity and central adiposity and possibly changes in immune function. The general recommendation according to the American cancer Society ${ }^{62}$ is for adults to undertake a minimum of 30 minutes of at least moderate intensity physical activity on at least 5 days a week. Previously sedentary men over age 40 years, women over age 50 years, adults with chronic disease, or risk factor for cardiovascular disease should consult their health care provider before starting a regular exercise program. Cancer patients should ask their doctors about an appropriate physical activity program.

4. Diet: evidence suggests a strong association between dietary factors and cancer and supports the beneficial effects of implementing dietary changes like increasing fruit and vegetable consumption. Major national efforts to help improve food related behavior, such as the "5-A Day for Better Health Program"78 have been launched since the 1980s and resulted in improved consumers' awareness. ${ }^{79,80}$ Further adherence to the American Cancer Society recommendations for healthy diet ${ }^{62}$ would constitute another step in the right direction. These include: 1) eating five or more servings of vegetables and fruits each day. The best way to eat vegetables and fruit is the natural way, without processing and not in the form of pills; 2) choosing whole grains (eg, rice, bread, pasta, and cereals made of wheat, oats, and barley) over processed refined grains and sugars such as pastries, sweetened cereals, and other high-sugar foods; 3) limiting intake of processed meats and red meats especially those with high fat (eg, fish, poultry, or beans instead of beef, pork, and lamb or using lean cuts and small portions). It is recommended to prepare meat by baking, broiling, or poaching rather than by 
frying or charbroiling and to substitute vegetable oils for butter or lard; and 4) choosing foods that help maintain a healthful weight.

5. Vitamins and supplements: consumers are greatly interested in the incidence of disease reduction by an inexpensive micronutrient intervention. The few interventions and clinical trials done in human populations designed to test whether supplements can reduce cancer risk have yielded disappointing and conflicting results. ${ }^{91,101}$ Many studies using high doses of single nutrients have shown no benefit and have even shown potential harm. ${ }^{99,102-104}$ Consequently, there are currently no consistent recommendations for the use of supplements and vitamins in the general population for cancer prevention. Food is the best source of vitamins and minerals and there is good evidence that a diet rich in vegetables, fruits, and other plant-based foods may reduce the risk of cancer as noted above, but there is no evidence at this time that supplements can reduce cancer risk. Future and ongoing research should provide a better guidance in the association between specific supplements and vitamins such as vitamin D and specific cancer risk. Although people obtain some vitamin $\mathrm{D}$ from dietary sources, most vitamin $\mathrm{D}$ is made in the body after the skin is exposed to sunlight. Despite the known and potential health benefits of vitamin D, increasing sun exposure may, however, increase the risk of skin cancer and caution should be exercised by using sun protection when UV levels are moderate or higher. ${ }^{89}$

6. Alcohol: alcohol consumption has been linked to the increased risk of many cancers. The American Cancer Society recommends that people who drink alcohol limit their intake to no more than two drinks per day for men and one drink a day for women. ${ }^{62}$ The recommended limit is lower for women because of their smaller body size and their metabolism. The American Cancer Society recognizes that while alcohol use has been linked to several types of cancer and other health risks, this is complicated by the fact that low to moderate alcohol intake may be linked with decreased risk of heart disease. In view of the potential cancer risk involved, however, this should not be a reason for adults who currently do not drink alcohol to start, as there are many other ways of reducing heart disease risk, including avoiding smoking, eating a diet low in saturated and trans fats, maintaining a healthy weight, staying physically active on a regular basis, and controlling blood pressure and cholesterol. ${ }^{62}$

\section{Disclosure}

The authors declare no conflicts of interest in this work.

\section{References}

1. NCI Drug Dictionary. Available at: http://www.cancer.gov/dictionary/? CdrID=439419. Accessed February 28, 2011.

2. The Health Consequences of Smoking: a Report of the Surgeon General. Atlanta, GA: US Department of Health and Human Services, Centers for Disease Control and Prevention, National Center for Chronic Disease Prevention and Health Promotion, Office on Smoking and Health; 2004.

3. Byers T, Barrera E, Fontham ET, et al. American Cancer Society Incidence and Mortality Ends Committee. A midpoint assessment of the American Cancer Society challenge goal to halve the US cancer mortality rates between the years 1990 and 2015. Cancer. 2006;107: 396-405.

4. Jemal A, Thun MJ, Ries LA, et al. Annual report to the nation on the status of cancer, 1975-2005, featuring trends in lung cancer, tobacco use, and tobacco control. J Natl Cancer Inst. 2008;100: $1672-1694$.

5. NIH state-of-the-science conference statement on tobacco use: prevention, cessation, and control. Ann Intern Med. 2006;145: 839-844.

6. Cokkinides V, Bandi P, McMahon C, Jemal A, Glynn T, Ward E. Tobacco control in the United States - recent progress and opportunities. CA Cancer J Clin. 2009;59:352-365.

7. McBride CM, Ostroff JS. Teachable moments for promoting smoking cessation: the context of cancer care and survivorship. Cancer Control. 2003;10:325-333.

8. Travis LB, Rabkin CS, Brown LM, et al. Cancer survivorship - genetic susceptibility and second primary cancers: research strategies and recommendations. J Natl Cancer Inst. 2006;98:15-25.

9. Parsons A, Daley A, Begh R, Aveyard P. Influence of smoking cessation after diagnosis of early stage lung cancer on prognosis: systematic review of observational studies with meta-analysis. $B M J$. 2010;340:b5569.

10. Hecht SS. Cigarette smoking and lung cancer: chemical mechanisms and approaches to prevention. Lancet Oncol. 2002;3:461-469.

11. Flegal KM, Carroll MD, Ogden CL, J Johnson CL. Prevalence and trends in obesity among US adults, 1999-2000. JAMA. 2002;288: 1723-1727.

12. Bianchini F, Kaaks R, Vainio H. Overweight, obesity and cancer risk. Lancet Oncol. 2002;3:565-574.

13. Jenks S. Researchers explore mechanisms that may link obesity and cancer. J Natl Cancer Inst. 2010;102:519-521.

14. Calle EE, Rodriguez C, Walker-Thurmond K, et al. Overweight, obesity, and mortality from cancer in a prospectively studied cohort of US adults. $N$ Engl $J$ Med. 2003;348:1625-1638.

15. Vainio H, Bianchini F. IARC Handbooks of Cancer Prevention. Volume 6: Weight Control and Physical Activity. Lyon, France: IARC Press; 2002.

16. Anand P, Kunnumakkara AB, Kunnumakara AB, et al. Cancer is a preventable disease that requires major lifestyle changes. Pharm Res. 2008;25:2097-20116.

17. American Institute for Cancer Research. Available at: http://www.aicr. org/site/News. Accessed February 19, 2010.

18. Toniolo PG, Levitz M, Zeleniuch-Jacquotte A, et al. A prospective study of endogenous estrogens and breast cancer in postmenopausal women. J Nat Cancer Inst. 1995;87:190-197.

19. Dai Q, Gao YT, Shu XO, et al. Oxidative stress, obesity, and breast cancer risk: results from the Shanghai Women's Health Study. J Clin Oncol. 2009;27:2482-2488.

20. Mobley JA, Brueggemeier RW. Estrogen receptor-mediated regulation of oxidative stress and DNA damage in breast cancer. Carcinogenesis. 2004;25:3-9. 
21. Bhat HK, Calaf G, Hei TK, Loya T, Vadgama JV. Critical role of oxidative stress in estrogen-induced carcinogenesis. Proc Natl Acad Sci US A. 2003;100:3913-3918.

22. Zhu BT, Conney AH. Functional role of estrogen metabolism in target cells: review and perspectives. Carcinogenesis. 1998;19:1-27.

23. Yager JD. Endogenous estrogens as carcinogens through metabolic activation. J Natl Cancer Inst Monogr. 2000:67-73.

24. Cavalieri E, Frenkel K, Liehr JG, Rogan E, Roy D. Estrogens as endogenous genotoxic agents: DNA adducts and mutations. J Natl Cancer Inst Monogr. 2000:75-93.

25. Jefcoate CR, Liehr JG, Santen RJ, et al. Tissue-specific synthesis and oxidative metabolism of estrogens. J Natl Cancer Inst Monogr. 2000: 95-112.

26. Emerit I. Reactive oxygen species, chromosome mutation, and cancer: possible role of clastogenic factors in carcinogenesis. Free Radic Biol Med. 1994;16:99-109.

27. Loeb LA. Endogenous carcinogenesis: molecular oncology into the twenty-first century - Presidential address. Cancer Res. 1989;49: 5489-5496.

28. Zheng W, Chow WH, Yang G, et al. The Shanghai Women's Health Study: rationale, study design, and baseline characteristics. Am J Epidemiol. 2005;162:1123-1131.

29. Gago-Dominguez M, Castelao JE, Pike MC, Sevanian A, Haile RW. Role of lipid peroxidation in the epidemiology and prevention of breast cancer. Cancer Epidemiol Biomarkers Prev. 2005;14:2829-2839.

30. Gago-Dominguez M, Jiang X, Esteban CJ. Lipid peroxidation and the protective effect of physical exercise on breast cancer. Med Hypotheses. 2007;68:1138-1143.

31. Goodwin PJ. Insulin in the adjuvant breast cancer setting: a novel therapeutic target for lifestyle and pharmacologic interventions? J Clin Oncol. 2008;26:833-834.

32. Lagergren J, Bergström R, Nyrén O. Association between body mass and adenocarcinoma of the esophagus and gastric cardia. Ann Intern Med. 1999;130:883-890.

33. Friedenreich CM, Orenstein MR. Physical activity and cancer prevention: etiological evidence and biological mechanism. J Nutr. 2002;132(11 Suppl):3456S-3464S.

34. Lee I, Oguma Y. Physical activity. In: Schottenfeld D, Fraumeni JF, editors. Cancer Epidemiology and Prevention. 3rd ed. New York: Oxford University Press; 2006.

35. McTiernan A, editor. Cancer Prevention and Management Through Exercise and Weight Control. Boca Raton, FL: Taylor and Francis Group, LLC; 2006.

36. Wolin KY, Yan Y, Colditz GA, Lee IM. Physical activity and colon cancer prevention: a meta-analysis. Br J Cancer. 2009;100:611-616.

37. Slattery ML. Physical activity and colorectal cancer. Sports Medicine. 2004;34:239-252.

38. World Cancer Research Fund and American Institute for Cancer Research Food, nutrition, physical activity and the prevention of cancer: a global perspective. Washington: American Institute for Cancer Research; 2007.

39. Monninkhof EM, Elias SG, Vlems FA, et al. Physical activity and breast cancer: a systematic review. Epidemiology. 2007;18:137-157.

40. McTiernan A, Tworoger SS, Rajan KB, et al. Effect of exercise on serum estrogens in postmenopausal women: a 12-month randomized clinical trial. Cancer Res. 2004;64:2923-2928.

41. Chan MF, Dowsett M, Folkerd E, et al. Usual physical activity and endogenous sex hormones in postmenopausal women: the European prospective investigation into cancer-Norfolk population study. Cancer Epidemiol Biomarkers Prev. 2007;16:900-905.

42. Voskuil DW, Monninkhof EM, Elias SG, Vlems FA, van Leeuwen FE. Physical activity and endometrial cancer risk, a systematic review of current evidence. Cancer Epidemiol Biomarkers Prev. 2007;16: 639-648

43. Tardon A, Lee WJ, Delgado-Rodriguez M, et al. Leisure-time physical activity and lung cancer: a meta-analysis. Cancer Causes Control. 2005;16:389-397.
44. Steindorf K, Friedenreich C, Linseisen J, et al. Physical activity and lung cancer risk in the European Prospective Investigation into Cancer and Nutrition Cohort. Int J Cancer. 2006;119:2389-2397.

45. Bak H, Christensen J, Thomsen BL, et al. Physical activity and risk for lung cancer in a Danish cohort. Int J Cancer. 2005;116:439-444.

46. Sinner P, Folsom AR, Harnack L, Eberly LE, Schmitz KH. The association of physical activity with lung cancer incidence in a cohort of older women: the Iowa Women's Health Study. Cancer Epidemiol Biomarkers Prev. 2006;15:2359-2363.

47. Alfano CM, Klesges RC, Murray DM, et al. Physical activity in relation to all-site and lung cancer incidence and mortality in current and former smokers. Cancer Epidemiol Biomarkers Prev. 2004;13: 2233-2241.

48. Michaud DS, Giovannucci E, Willett WC, Colditz GA, Stampfer MJ, Fuchs CS. Physical activity, obesity, height, and the risk of pancreatic cancer. JAMA. 2001;286:921-929.

49. Hanley AJ, Johnson KC, Villeneuve PJ, Mao Y. Physical activity, anthropometric factors and risk of pancreatic cancer: results from the Canadian enhanced cancer surveillance system. Int J Cancer. 2001; 94:140-147.

50. Patel AV, Rodriguez C, Bernstein L, Chao A, Thun MJ, Calle EE. Obesity, recreational physical activity, and risk of pancreatic cancer in a large US Cohort. Cancer Epidemiol Biomarkers Prev. 2005;14: 459-466.

51. Lin Y, Kikuchi S, Tamakoshi A, et al. Obesity, physical activity and the risk of pancreatic cancer in a large Japanese cohort. Int J Cancer. 2007;120:2665-26671.

52. Bao Y, Michaud DS. Physical activity and pancreatic cancer risk: a systematic review. Cancer Epidemiol Biomarkers Prev. 2008; 17:2671-2682.

53. Nilsen TI, Romundstad P, Vatten LJ. Recreational physical activity and risk of prostate cancer: a prospective population-based study in Norway (the HUNT study). Int J Cancer. 2006;119:2943-2947.

54. Patel AV, Rodriguez C, Jacobs EJ, et al. Recreational physical activity and risk of prostate cancer in a large cohort of US men. Cancer Epidemiol Biomarkers Prev. 2005;14:275-279.

55. Giovannucci EL, Liu Y, Leitzmann MF, Stampfer MJ, Willett WC. A prospective study of physical activity and incident and fatal prostate cancer. Arch Intern Med. 2005;165:1005-1010.

56. Orsini N, Bellocco R, Bottai M, et al. A prospective study of lifetime physical activity and prostate cancer incidence and mortality. $\mathrm{Br} J$ Cancer. 2009;101:1932-1938.

57. Johnsen NF, Tjønneland A, Thomsen BL, et al. Physical activity and risk of prostate cancer in the European Prospective Investigation into Cancer and Nutrition (EPIC) cohort. Int J Cancer. 2009; 125:902-908.

58. Moore SC, Peters TM, Ahn J, et al. Age-specific physical activity and prostate cancer risk among white men and black men. Cancer. 2009; 115:5060-5070.

59. O'Rorke MA, Cantwell MM, Cardwell CR. Can physical activity modulate pancreatic cancer risk? A systematic review and meta-analysis. Int J Cancer. 2010;126:2957-2968.

60. Nöthlings U, Wilkens LR, Murphy SP, Hankin JH, Henderson BE, Kolonel LN, et al. Body mass index and physical activity as risk factors for pancreatic cancer: the Multiethnic Cohort Study. Cancer Causes Control. 2007;18:165-175.

61. Berrington de Gonzalez A, Sweetland S, Spencer E. A meta-analysis of obesity and the risk of pancreatic cancer. Br J Cancer. 2003;89: 519-523.

62. Kushi L, Byers T, Doyle D, et al. American Cancer Society Guidelines on Nutrition and Physical Activity for Cancer Prevention: reducing the Risk of Cancer with Healthy Food Choices and Physical Activity. $C A$ Cancer J Clin. 2006;56:254-281.

63. Doll R, Peto R. The causes of cancer: quantitative estimates of avoidable risks of cancer in the United States today. J Natl Cancer Inst. 1981;66: 1191-1308.

64. Abdulla M, Gruber P. Role of diet modification in cancer prevention. Biofactors. 2000;12:45-51. 
65. Food, nutrition, physical activity, and the prevention of cancer: a global perspective. World Cancer Research Fund and American Institute for Cancer Research. Available at: http://www.dietandcancerreport.org/. Accessed August 19, 2009.

66. Divisi D, Di Tommaso S, Salvemini S, et al. Diet and Cancer. Acta Biomed. 2006;77:118-123.

67. World Health Organization. Available at: http://www.who.int/diet physicalactivity/publications/facts/cancer/en/. Accessed February 19, 2011.

68. Key TJ, Schatzkin A, Willett WC, Allen NE, Spencer EA, Travis RC. Diet, nutrition and prevention of cancer. Public Health Nutr. 2004;7: 187-200.

69. Go VL, Wong DA, Butrum R. Diet, nutrition and cancer prevention: where are we going from here? J Nutr. 2001;131(11 Suppl):3121S-3126S.

70. Gonzalez CA, Riboli E. Diet and cancer prevention; Contribution from European Prospective Investigation into Cancer and Nutrition (EPIC) study. Eur J Cancer. 2010;46:2555-2562.

71. Leischauer AT, Arab L. Garlic and cancer: a critical review of the epidemiologic literature. J Nutr. 2001;131(3S):1032S-1040S.

72. Setiawan VW, Yu GP, Lu QY, et al. Allium vegetables and stomach cancer risk in China. Asian Pac J Cancer Prev. 2005;6:387-395.

73. Hsing AW, Chokkalingam AP, Gao YT, et al. Allium vegetables and risk of prostate cancer: a population-based study. J Natl Cancer Inst. 2002;94:1648-1651.

74. Verhoeven DT, Goldbohm RA, van Poppel G, Verhagen H, van den Brandt PA. Epidemiological studies on brassica vegetables and cancer risk. Cancer Epidemiol Biomarkers Prev. 1996;5:733-748.

75. Bonnesen C, Eggleston IM, Hayes JD. Dietary indoles and isothiocyanates that are generated from cruciferous vegetables can both stimulate apoptosis and confer protection against DNA damage in human colon cell lines. Cancer Res. 2001;61:6120-6130.

76. Higdon JV, Delage B, Williams DE, Dashwood RH. Cruciferous vegetables and human cancer risk: epidemiologic evidence and mechanistic basis. Pharmacol Res. 2007;55:224-236.

77. Lee SA, Fowke JH, Lu W, et al. Cruciferous vegetables, the GSTP1 Ile105Val genetic polymorphism, and breast cancer risk. Am J Clin Nutr. 2008;87:753-760.

78. Krebs-Smith SM, Cook A, Subar AF, Cleveland L, Friday J. US adults' fruit and vegetable intakes, 1989 to 1991: a revised baseline for the Healthy People 2000 objective. Am J Public Health. 1995;85: $1623-1629$.

79. Tippett KS, CypelYS. Design, and Operation. The Continuing Survey of Food Intakes by Individuals and the Diet and Health Knowledge Survey, 1994-1996. Nationwide Food Surveys Report No. 96-1, Agricultural Research Service. Washington, DC: US Department of Agriculture; 1998.

80. Goldberg KB, Goldberg P, editors. Americans closer to eating "5-ADay", food survey finds. Cancer Lett. 23:6:1997.

81. Nahleh Z, Tabbara IA. Complementary and alternative medicine in breast cancer patients. Palliat Support Care. 2003;1:267-273.

82. Ames BN. A theory of evolutionary allocation of scarce micronutrients by enzyme triage: adequate micronutrient nutrition to delay the degenerative diseases of aging. Proc Natl Acad Sci U S A. 2006;103: 17589-17594.

83. Ames BN, McCann JC. Foreword: prevention of cancer, and the other degenerative diseases of aging, through nutrition. In: Knasmüller S, DeMarini D, Johnson I, Gerhäuser C, editors. Chemoprevention of Cancer and DNA Damage by Dietary Factors. Weinheim, Germany: Wiley-VCH; 2009.

84. Ames BN. Optimal micronutrients delay mitochondrial decay and age-associated diseases. Mech Ageing Dev. 2010;131:473-479.

85. Ames BN. Prevention of mutation, cancer, and other age-associated diseases by optimizing micronutrient intake. J Nucleic Acids. 2010; 2010:725071

86. McCann JC, Ames BN. Is there convincing biological or behavioral evidence linking vitamin D deficiency to brain dysfunction? FASEB J. 2008;22:982-1001.
87. McCann JC, Ames BN. Vitamin K, an example of triage theory: is micronutrient inadequacy linked to diseases of aging? Am J Clin Nutr. 2009;90:889-907.

88. Moshfegh A, Goldman J, Cleveland L. What We Eat in America, NHANES 2001-2002: usual Nutrient Intakes from Food Compared to Dietary Reference Intakes. US Department of Agriculture, Agricultural Research Service; 2005.

89. McCann JC, Ames BN. Evidence required for causal inferences about effects of micronutrient deficiencies during development on brain health - DHA, choline, iron, and vitamin D. In: Packer L, Sees H, Eggersdorfer M, Cadenas E, editors. Micronutrients and Brain Health. London, UK: CRC Press; 2009.

90. Ames BN, McCann JC, Stampfer MJ, Willett WC. Evidence-based decision making on micronutrients and chronic disease: long-term randomized controlled trials are not enough. Am J Clin Nutr. 2007; 86:522-524.

91. Ross AC, Manson JE, Abrams SA, et al. The 2011 Report on Dietary Reference Intakes for Calcium and Vitamin D from the Institute of Medicine: what Clinicians Need to Know. J Clin Endocrinol Metab. 2011;96:53-58.

92. Holick MF. Evolution and function of vitamin D. Recent Results. Cancer Res. 2003;164:3-28.

93. Lappe JM, Travers-Gustafson D, Davies KM, Recker RR, Heaney RP. Vitamin D and calcium supplementation reduces cancer risk: results of a randomized trial. Am J Clin Nutr. 2007;85: 1586-1591.

94. Glovannuci E. Vit-D and cancer incidence in Harvard cohorts. Ann Epidemiol. 2009;19:84-88.

95. Lipkin M, Newmark H. Effect of added dietary calcium on colonic epithelial-cell proliferation in subjects at high risk for familial colonic cancer. N Engl J Med. 1985;313:1381-1384.

96. Holt P, Arber N, Halmos B, et al. Colonic epithelial cell proliferation decreases with increasing levels of serum 25-hydroxy vitamin D. Cancer Epidemiol Biomarkers Prev. 2002;11:113-119.

97. Lieberman DA, Prindiville S, Weiss DG, Willett W. Risk factors for advanced colonic neoplasia and hyperplastic polyps in asymptomatic individuals. JAMA. 2003;290:2959-2967.

98. Freedman DM, Looker AC, Chang SC, Graubard BI. Prospective study of serum vitamin D and cancer mortality in the United States. J Natl Cancer Inst. 2007;99:1594-1602.

99. Chlebowski RT, Johnson KC, Kooperberg C, et al. Calcium plus vitamin D supplementation and the risk of breast cancer. J Natl Cancer Inst. 2008;100:581-1591.

100. Garland CF, Gorham ED, Mohr SB, et al. Vitamin D and prevention of breast cancer - pooled analysis. J Steroid Biochem Mol Biol. 2007; 103:708-711.

101. Ahn J, Peters U, Albanes D, et al. Serum vitamin D concentration and prostate cancer risk: a nested case-control study. J Natl Cancer Inst. 2008;100:796-804.

102. Ba OY, Ng K, Wolpin BM, Michaud DS, Giovannucci E, Fuchs CS. Predicted vitamin D status and pancreatic cancer risk two prospective cohort studies. Br J Cancer. 2010;109:1422-1427.

104. Blot W, Li J, Taylor P, et al. Nutrition intervention trials in Linxian, China; supplementation with specific vitamin/mineral combinations, cancer incidence and disease-specific mortality in the general population. J Natl Cancer Inst. 1993;85:1483-1492.

105. The Alpha-Tocopherol, Beta Carotene Cancer Prevention Study Group. The effect of vitamin $\mathrm{E}$ and beta carotene on the incidence of lung cancer and other cancers in male smokers. N Engl J Med. 1994; 330:1029-1035.

106. Omenn G, Goodman G, Thornquist M, et al. Effects of a combination of beta carotene and vitamin A on lung cancer and cardiovascular disease. N Engl J Med. 1996;334:1150-1155.

107. Henneken SC, Buring J, Manson J, et al. Lack of effect of long term supplementation with beta-carotene on the incidence of malignant neoplasms and cardiovascular disease. N Engl J Med. 1996;334: $1145-1149$. 
108. Boffetta P, Hashibe M. Alcohol and cancer. Lancet Oncol. 2006;7: 149-156.

109. Allen NE, Beral V, Casabonne D, et al. Moderate alcohol intake and cancer incidence in women. J Natl Cancer Inst. 2009;101:296-305.

110. Freudenheim JL, Ritz J, Smith-Warner S, et al. Alcohol consumption and Risk of Lung Cancer: a pooled analysis of cohort studies. Am J Clin Nutr. 2005;82:657-667.

111. Kwna M, Kushi L, Weltzien E, et al. Alcohol consumption and breast cancer recurrence and survival among women with early-stage breast cancer: the life after cancer epidemiology study. J Clin Oncol. 2010;28:4410-4416.
112. Vogel VG, Costantino JP, Wickerham DL, et al. Update of the National Surgical Adjuvant Breast and Bowel Project Study of Tamoxifen and Raloxifene (STAR) P-2 Trial: preventing breast cancer. Cancer Prev Res (Phila). 2010;3:696-706.

113. US Food and Drug Administration. Available at: http://www.fda.gov/ NewsEvents/Newsroom. Accessed February 26, 2011.

114. Strope SA, Andriole GL. Update on chemoprevention for prostate cancer. Curr Opin Urol. 2010;20:194-197.

International Journal of General Medicine

\section{Publish your work in this journal}

The International Journal of General Medicine is an international, peer-reviewed open-access journal that focuses on general and internal medicine, pathogenesis, epidemiology, diagnosis, monitoring and treatment protocols. The journal is characterized by the rapid reporting of reviews, original research and clinical studies across all disease areas.

\section{Dovepress}

A key focus is the elucidation of disease processes and management protocols resulting in improved outcomes for the patient. The manuscript management system is completely online and includes a very quick and fair peer-review system. Visit http://www.dovepress.com/ testimonials.php to read real quotes from published authors.

Submit your manuscript here: http://www.dovepress.com/international-journal-of-general-medicine-journal 